\title{
EL DERECHO DE LOS EXTRANJEROS A UTILIZAR LOS SERVICIOS DE LA SEGURIDAD SOCIAL
}

ITHE RIGHT OF FOREIGNERS TO HAVE SOCIAL SECURITY

\author{
Egla Cornelio Landero \\ Alfredo Islas Colín \\ Universidad Juárez Autónoma de Tabasco. México/Mexico \\ liclandero@hotmail.com \\ islas40@hotmail.com
}

Recibido/Received: 31/01/2015

Modificado/Modified: 24/04/2015

Aceptado/Accepted: 29/04/2015

\section{RESUMEN}

El extranjero es la persona que viene de un país y entra en otra soberanía, quedando sus derechos limitados conforme al derecho que reconoce la Ley Fundamental del país al que llega, en México el artículo 33 de la Constitución Política de los Estados Unidos Mexicanos, refiere que son extranjeros los que no posean las calidades determinadas en el artículo 30 de la misma Constitución y gozarán de los derechos humanos y garantías que reconoce la misma Constitución. El Derecho de Seguridad Social es un derecho humano de acceso a la salud, a la asistencia médica y medios de subsistencias que necesita el individuo para sobrevivir.

\section{PALABRAS CLAVE}

Extranjero, migrante, Derechos Humanos, Seguridad Social.

\section{SUMARIO}

1. Nacional y Extranjero. 2. Derechos humanos de los extranjeros en México. 3. Derecho de los extranjeros a utilizar Seguridad Social. 4. Conclusión. Bibliografía.

\begin{abstract}
The foreigner is a person who comes from a country and enters another sovereignty, leaving their limited rights under the law that recognizes the Basic Law of the country they arrive in Mexico Article 33 of the Political Constitution of the Mexican United States, states that foreigners are those who do not possess the qualifications specified in Article 30 of the constitution and enjoy human rights and guarantees recognized by the Constitution. The Social Security Law is a human right of access to health, medical assistance and means of subsistence that requires the individual to survive.
\end{abstract}

\section{KEYWORDS}

Foreigner, migrant, Human Rights, Social Security.

\section{CONTENTS}

1. Nationality and Foreigner. 2. Human Rights of Foreigners in Mexico. 3. Rights of Foreigners to enjoy Social Security. 4. Conclusion. References. 


\section{NACIONAL Y EXTRANJERO}

Para abordar el tema de nacional y extranjero, iniciaremos por definir a qué se le dice nacional, de modo, que se puede decir que es pertenencia o integración natural con un grupo étnico y cultural específico, o también nacional se dice a una persona perteneciente o nativo de una nación, o grupo de personas que hablan el mismo idioma, cultura y del mismo lugar. En México el artículo 30 de la Constitución Política de los Estados Unidos Mexicanos, indica que la nacionalidad de mexicano se adquiere por nacimiento o por naturalización, y en sus incisos A y B, con sus respectivas fracciones estipula bajo qué condiciones se es mexicano por nacimiento considerando entre estos a los ius soli (Soberanes e Islas, 2013) que nazcan en territorio de la República (independientemente de la nacionalidad de los padres (Arredondo Galván, 2005) así como los ius sanguinis, que nazcan en el extranjero hijos de padres mexicanos, o de padre o madre mexicana (por nacimiento o por naturalización), así como los que nazcan a bordo de aeronaves mexicanas, o por naturalización, que son los extranjeros que obtengan de la Secretaría de Relaciones carta de naturalización, así como la mujer o el varón o extranjeros que contraigan matrimonio con varón o con mujer mexicanos, que tengan o establezcan su domicilio dentro del territorio nacional y cumplan con los demás requisitos que al efecto señale la Ley (Witker, 2000). Además en su artículo 73, fracción XVI, establece que es facultad del Congreso de la Unión expedir leyes sobre nacionalidad, condición jurídica de los extranjeros, ciudadanía, naturalización, emigración e inmigración.

Ley de Nacionalidad, refiere a la nacionalidad mexicana por naturalización, en el Artículo 19.- El extranjero que pretenda naturalizarse mexicano deberá: I. Presentar solicitud a la Secretaría en la que manifieste su voluntad de adquirir la nacionalidad mexicana; II. Formular las renuncias y protesta a que se refiere el artículo 17 de este ordenamiento; La Secretaría no podrá exigir que se formulen tales renuncias y protestas sino hasta que se haya tomado la decisión de otorgar la nacionalidad al solicitante. La carta de naturalización se otorgará una vez que se compruebe que éstas se han verificado. III. Probar que sabe hablar español, conoce la historia del país y está integrado a la cultura nacional; y IV. Acreditar que ha residido en territorio nacional por el plazo que corresponda conforme al artículo 20 de esta Ley. Para el correcto cumplimiento de los requisitos a que se refiere este artículo, se estará a lo dispuesto en el reglamento de esta Ley. Artículo 20.- El extranjero que pretenda naturalizarse mexicano deberá acreditar que ha residido en territorio nacional cuando menos durante los últimos cinco años inmediatos anteriores a la fecha de su solicitud.

México se encuentra entre las primeras diez naciones del continente en cuanto a la proporción de población extranjera dentro de su población total residente. Con las cifras del censo 2010 podemos saber que en México viven 961.121 personas que nacieron en otro país, prácticamente son el doble de las que había en el año 2000, si comparamos esta cifra con los 112.336.538 personas contabilizadas en todo el país, equivale a decir que 9 de cada mil habitantes en México nacieron en otro país; que en términos porcentuales representa el $0.9 \%$ del total de la población residente en México (INEGI, 2011).

Extranjero es la persona que se encuentra en una nación de la que no es originario; en un sentido gramatical es el natural de una nación con respecto a los naturales de cualquier otra. La Constitución Política de los Estados Unidos Mexicanos, a partir de la reforma a Derechos Humanos también reformó el artículo que regula el derecho de los extranjeros y en el artículo 33 establece:

"Son personas extranjeras las que no posean las calidades determinadas en el artículo 30 constitucional y gozarán de los derechos humanos y garantías que reconoce esta Constitución. El Ejecutivo de la Unión, previa audiencia, podrá expulsar del territorio 
nacional a personas extranjeras con fundamento en la ley, la cual regulará el procedimiento administrativo, así como el lugar y tiempo que dure la detención. Los extranjeros no podrán de ninguna manera inmiscuirse en los asuntos políticos del país."

Extranjero es la persona que no posea la calidad de mexicano, conforme lo previene el artículo 30 de la Constitución. Los extranjero pueden permanecer en territorio nacional con las condiciones de estancia de visitante, residente temporal o residente permanente, (Federación, 2011). Los tratados internacionales regulan la condición jurídica de los extranjeros en el derecho mexicano, a partir de la reforma al artículo $1^{\circ}$ Constitucional (Robles Farías, 1998).

Extranjeros bajo condiciones de estancias de visitantes que son:

1. El visitante sin permiso para realizar actividades remuneradas y permanecer en el territorio por un tiempo ininterrumpido no mayor a ciento ochenta días;

2. El visitante con permiso para realizar actividades remuneradas, es el extranjero que cuente con una oferta de empleo con una invitación por parte de alguna autoridad o institución académica, artística, deportiva o cultural por la cual perciba una remuneración en el país, o venga a desempeñar una actividad remunerada por temporada estacional en virtud de acuerdos interinstitucionales celebrados con entidades extranjeras, para permanecer en territorio nacional por un tiempo ininterrumpido no mayor a ciento ochenta días, contados a partir de la fecha de entrada;

3. Visitante regional, es el extranjero nacional o residente de los países vecinos para ingresar a las regiones fronterizas con derechos a entrar y salir de las mismas cuantas veces lo desee, sin que su permanencia exceda de tres días y sin permisos para recibir remuneración en el país;

4. Visitante trabajador fronterizo, autoriza al extranjero que sea nacional de los países con los cuales los Estados Unidos Mexicanos comparten límites territoriales, para permanecer hasta por un año en las entidades federativas que determine la Secretaría. El visitante trabajador fronterizo contará con permiso para trabajar a cambio de una remuneración en el país, en la actividad relacionada con la oferta de empleo con que cuente y con derecho a entrar y salir del territorio nacional cuantas veces lo desee.

5. Visitante por razones humanitarias. Se autorizará esta condición de estancia a los extranjeros que se encuentren en cualquiera de los siguientes supuestos: a) Ser ofendido, víctima o testigo de algún delito cometido en territorio nacional. Al ofendido, víctima o testigo de un delito a quien se autorice la condición de estancia de Visitante por Razones Humanitarias, se le autorizará para permanecer en el país hasta que concluya el proceso, al término del cual deberán salir del país o solicitar una nueva condición de estancia, con derecho a entrar y salir del país cuantas veces lo desee y con permiso para trabajar a cambio de una remuneración en el país. Posteriormente, podrá solicitar la condición de estancia de residente permanente; b) Ser niña, niño o adolescente migrante no acompañado, en términos del artículo 74 de la Ley de Migración; c) Ser solicitante de asilo político, de reconocimiento de la condición de refugiado o de protección complementaria del Estado Mexicano, hasta en tanto no se resuelva su situación migratoria. Si la solicitud es positiva se les otorgará la condición de estancia de residente permanente, en términos del artículo 54 de la Ley de Migración.

6. Visitante con fines de adopción. Autoriza al extranjero vinculado con un proceso de adopción en los Estados Unidos Mexicanos, a permanecer en el país hasta en tanto se dicte la resolución ejecutoriada y en su caso, se inscriba en el registro civil la nueva acta del niño, niña o adolescente adoptado, así como se expida el pasaporte respectivo y todos los trámites 
necesarios para garantizar la salida del niño, niña o adolescente del país. La expedición de esta autorización solo procederá respecto de ciudadanos de países con los que los Estados Unidos Mexicanos haya suscrito algún convenio en la materia.

El artículo 53, de la ley de cuenta dispone que: Los visitantes, con excepción de aquéllos por razones humanitarias y de quienes tengan vínculo con mexicano o con extranjero con residencia regular en México, no podrán cambiar de condición de estancia y tendrán que salir del país al concluir el período de permanencia autorizado.

Los residentes pueden ser temporal. Autoriza al extranjero para permanecer en el país por un tiempo no mayor a cuatro años, con la posibilidad de obtener un permiso para trabajar a cambio de una remuneración en el país, sujeto a una oferta de empleo con derecho a entrar y salir del territorio nacional cuantas veces lo desee y con derecho a la preservación de la unidad familiar por lo que podrá ingresar con o solicitar posteriormente la internación de las personas que se señalan a continuación, quienes podrán residir regularmente en territorio nacional por el tiempo que dure el permiso del residente temporal: a) Hijos del residente temporal y los hijos del cónyuge, concubinario o concubina, siempre y cuando sean niñas, niños y adolescentes y no hayan contraído matrimonio, o se encuentren bajo su tutela o custodia; b) Cónyuge; c) Concubinario, concubina o figura equivalente, acreditando dicha situación jurídica conforme a los supuestos que señala la legislación mexicana, y d) Padre o madre del residente temporal. Las personas a que se refieren los incisos anteriores serán autorizados para residir regularmente en territorio nacional bajo la condición de estancia de residente temporal, con la posibilidad de obtener un permiso para trabajar a cambio de una remuneración en el país sujeto a una oferta de empleo, y con derecho a entrar y salir del territorio nacional cuantas veces lo deseen. En el caso de que el residente temporal cuente con una oferta de empleo, se le otorgará permiso para trabajar a cambio de una remuneración en el país, en la actividad relacionada con dicha oferta de empleo.

Igualmente, se tiene al Residente temporal Estudiante, es el extranjero que permanece en el territorio nacional por el tiempo que duren los cursos, estudios, proyectos de investigación o formación que acredite que va a realizar en instituciones educativas pertenecientes al sistema educativo nacional, hasta la obtención del certificado, constancia, diploma, título o grado académico correspondiente, con derecho a entrar y salir del territorio nacional cuantas veces lo desee, con permiso para realizar actividades remuneradas cuando se trate de estudios de nivel superior, posgrado e investigación.

La autorización de estancia de los estudiantes está sujeta a la presentación por parte del extranjero de la carta de invitación o de aceptación de la institución educativa correspondiente y deberá renovarse anualmente, para lo cual el extranjero acreditará que subsisten las condiciones requeridas para la expedición de la autorización inicial. La autorización para realizar actividades remuneradas se otorgará por el Instituto cuando exista carta de conformidad de la institución educativa correspondiente y estará sujeta a una oferta de trabajo en actividades relacionadas con la materia de sus estudios. El residente temporal estudiante tendrá derecho a entrar y salir del territorio nacional cuantas veces lo desee y contará también con el derecho a la preservación de la unidad familiar.

El Residente permanente. Autoriza al extranjero para permanecer en el territorio nacional de manera indefinida, con permiso para trabajar a cambio de una remuneración en el país. El artículo 54 del Ley en cita dice que la condición de residente permanente el que se encuentre en nuestro país por I. Por razones de asilo político, reconocimiento de la condición de refugiado y protección complementaria o por la determinación de apátrida; II. Por el derecho a la preservación de la unidad familiar; III. Que sean jubilados o pensionados que perciban de un gobierno extranjero o de organismos internacionales o de empresas particulares por 
servicios prestados en el exterior, un ingreso que les permita vivir en el país; IV. Por decisión del Instituto, conforme al sistema de puntos que al efecto se establezca, en términos del artículo 57 de esta Ley; V. Porque hayan transcurrido cuatro años desde que el extranjero cuenta con un permiso de residencia temporal; VI. Por tener hijos de nacionalidad mexicana por nacimiento, y VII. Por ser ascendiente o descendente en línea recta hasta el segundo grado de un mexicano por nacimiento.

Por otra parte siguiente en este análisis sociológico, se pasa a tratar el tema de ciudadanía cualidad que corresponde también a ciudadano, es la cualidad jurídica que tiene toda persona física -hombre y mujer- estatal o nacional de una comunidad soberana, que le permite participar en los asuntos políticos de un Estado (Venegas Trejo, 2004), El artículo 34 de la Constitución Federal en México, dice que son ciudadanos de la República los varones y mujeres que, teniendo la calidad de mexicanos reúnen, además, los requisitos de haber cumplido 18 años y tener un modo honesto de vivir. Estos por principio natural y jurídico tienen prerrogativas como ciudadanos, al igual que obligaciones, las cuales poseen y solamente pueden ser suspendidas o perderla en su caso, como lo dispone la Norma Fundamental de la Nación.

Finalmente, se puede sostener que el extranjero es la persona que transita o permanece en un país del que no es nativo, bajo las condiciones de tránsito que dispone el país al que llega, poseyendo la salvaguarda de su integridad y el goce de y protección de su derecho humano.

\section{DERECHOS HUMANOS DE LOS EXTRANJEROS EN MÉXICO}

En la noción de los Derechos Humanos, hemos de dejar sentado que tenemos los derechos fundamentales que son los constitucionalmente enunciados en la Carta Magna de México, que se encuentran ampliamente reconocidos a partir del Artículo $1^{\circ}$ de la misma Carta, con los tratados internacionales de los que el Estado mexicano sea partes, así como las garantías para su protección (Castan Tobeñas, 1992).

En México, a partir de la reformas de los Derechos Humanos del 10 de junio de 2011, se estima que han sido reconocidos cabalmente los derechos de los extranjeros, pues antes a esa fecha sus derechos estaban limitados, sin embargo, en estos tiempos los extranjeros no tienen limitaciones solamente las previstas en el último párrafo del artículo 33 de la Constitución Política de los Estados Unidos Mexicanos, esto, que no deben inmiscuirse en los asuntos políticos del país.

En ese contexto, los extranjeros se encuentran incluidos en los derechos que refiere el artículo $1^{\circ}$ de la Citada Constitución que refiere: "En los Estados Unidos Mexicanos todas las personas gozarán de los Derechos Humanos reconocidos en esta Constitución y en los tratados internacionales de los que el Estado mexicano sea parte, así como las garantías para su protección, cuyo ejercicio no podrán restringirse ni suspenderse, salvo el caso y bajo las condiciones que esta Constitución establece (DOF: 2011). Tienen derecho a la educación, a la salud, al trabajo, al acceso a la información pública y a la petición, a la libertad de asociación, derecho a la garantía de audiencia y debido proceso, derecho al acceso a la justicia.

En el Derecho Internacional los derechos humanos de los extranjeros el Pacto Internacional de Derechos Civiles y Políticos el artículo 13 reconoce la libertad de tránsito, de ejercicio y disposición de derechos de los extranjeros que se halle legalmente en un territorio. En la Convención América sobre Derechos Humanos el artículo 22 refiere al 
Derecho de Circulación y de Residencia de los extranjeros, con ello, obvio que por el derecho Pro persona, le corresponde disfrutar y gozar de los derechos humanos que el país donde se encuentre le garantiza a sus nacionales, solamente con algunas restricciones determine por Ley, como dice el numeral 3 de dicha Convención para prevenir infracciones penales o para proteger la seguridad nacional, la seguridad o el orden públicos, la moral o la salud públicas o los derechos y libertades de los demás.

Sobre los derechos fundamentales de acceso a la información pública y de petición el Poder Judicial de la Federación, ha sostenido que los artículos 6o. y 8o. de la Constitución Política de los Estados Unidos Mexicanos, consagran en favor de las personas, los derechos fundamentales de acceso a la información pública y de petición, los cuales, obligan a las autoridades a dar la máxima publicidad a la información que posean y responder en breve término, de forma coherente y por escrito, a las solicitudes que hagan los ciudadanos. Estos derechos fundamentales tienen sus limitantes dentro del propio marco constitucional, en el caso del primero, que lo solicitado se encuentre reservado temporalmente hasta por un término de doce años, razones de interés público y seguridad nacional, y para el caso del segundo, únicamente se impone como prerrogativa para el suscribiente, que la solicitud formulada sea presentada de forma escrita, pacífica y respetuosa, amén de que dicho derecho se encuentra restringido para los extranjeros cuando su petición sea formulada en materia política. (DERECHOS FUNDAMENTALES, 2014).

En el derecho de acceso a la justicia los extranjeros a partir de la reforma a los artículos $1^{\circ}$, 11 y 33 Constitucional, no son personas con algún estatus de protección menor de derechos humanos, por lo que deben gozar plenamente de la tutela judicial efectiva, prevista tanto en sede internacional (artículo 25 de la Convención Americana sobre Derechos Humanos), como en el ámbito nacional (artículo 17 de la Constitución Federal), optando por privilegiar el acceso a la justicia y, por ende, limitando los casos en que por excepción, no puedan ser oídos. (EXTRANJEROS, 2012)

Finalmente, con la promulgación de la Ley de Migración en mayo de 2011, así como su Reglamento en 28 de septiembre de 2012, la primera establece en su artículo 2, lo siguiente:

Artículo 2. La política migratoria del Estado Mexicano es el conjunto de decisiones estratégicas para alcanzar objetivos determinados que con fundamento en los principios generales y demás preceptos contenidos en la presente Ley, se plasman en el Reglamento, normas secundarias, diversos programas y acciones concretas para atender el fenómeno migratorio de México de manera integral, como país de origen, tránsito, destino y retorno de migrantes.

Son principios en los que debe sustentarse la política migratoria del Estado mexicano los siguientes:

Respeto irrestricto de los derechos humanos de los migrantes, nacionales y extranjeros, sea cual fuere su origen, nacionalidad, género, etnia, edad y situación migratoria, con especial atención a grupos vulnerables como menores de edad, mujeres, indígenas, adolescentes y personas de la tercera edad, así como a víctimas del delito. En ningún caso una situación migratoria irregular preconfigurará por sí misma la comisión de un delito ni se prejuzgará la comisión de ilícitos por parte de un migrante por el hecho de encontrarse en condición no documentada.

Congruencia de manera que el Estado mexicano garantice la vigencia de los derechos que reclama para sus connacionales en el exterior, en la admisión, ingreso, permanencia, tránsito, deportación y retorno asistido de extranjeros en su territorio.

Enfoque integral acorde con la complejidad de la movilidad internacional de personas, que atienda las diversas manifestaciones de migración en México como país de origen, tránsito, 
destino y retorno de migrantes, considerando sus causas estructurales y sus consecuencias inmediatas y futuras.

Responsabilidad compartida con los gobiernos de los diversos países y entre las instituciones nacionales y extranjeras involucradas en el tema migratorio.

Hospitalidad y solidaridad internacional con las personas que necesitan un nuevo lugar de residencia temporal o permanente debido a condiciones extremas en su país de origen que ponen en riesgo su vida o su convivencia, de acuerdo con la tradición mexicana en este sentido, los tratados y el derecho internacional.

Facilitación de la movilidad internacional de personas, salvaguardando el orden y la seguridad. Este principio reconoce el aporte de los migrantes a las sociedades de origen y destino. Al mismo tiempo, pugna por fortalecer la contribución de la autoridad migratoria a la seguridad pública y fronteriza, a la seguridad regional y al combate contra el crimen organizado, especialmente en el combate al tráfico o secuestro de migrantes, y a la trata de personas en todas sus modalidades.

Complementariedad de los mercados laborales con los países de la región, como fundamento para una gestión adecuada de la migración laboral acorde a las necesidades nacionales.

Equidad entre nacionales y extranjeros, como indica la Constitución Política de los Estados Unidos Mexicanos, especialmente en lo que respecta a la plena observancia de las garantías individuales, tanto para nacionales como para extranjeros.

Reconocimiento a los derechos adquiridos de los inmigrantes, en tanto que los extranjeros con arraigo o vínculos familiares, laborales o de negocios en México han generado una serie de derechos y compromisos a partir de su convivencia cotidiana en el país, aún cuando puedan haber incurrido en una situación migratoria irregular por aspectos administrativos y siempre que el extranjero haya cumplido con las leyes aplicables.

Unidad familiar e interés superior de la niña, niño y adolescente, como criterio prioritario de internación y estancia de extranjeros para la residencia temporal o permanente en México, junto con las necesidades laborales y las causas humanitarias, en tanto que la unidad familiar es un elemento sustantivo para la conformación de un sano y productivo tejido social de las comunidades de extranjeros en el país.

Integración social y cultural entre nacionales y extranjeros residentes en el país con base en el multiculturalismo y la libertad de elección y el pleno respeto de las culturas y costumbres de sus comunidades de origen, siempre que no contravengan las leyes del país.

Facilitar el retorno al territorio nacional y la reinserción social de los emigrantes mexicanos y sus familias, a través de programas interinstitucionales y de reforzar los vínculos entre las comunidades de origen y destino de la emigración mexicana, en provecho del bienestar familiar y del desarrollo regional y nacional.

El Poder Ejecutivo determinará la política migratoria del país en su parte operativa, para lo cual deberá recoger las demandas y posicionamientos de los otros Poderes de la Unión, de los gobiernos de las entidades federativas y de la sociedad civil organizada, tomando en consideración la tradición humanitaria de México y su compromiso indeclinable con los derechos humanos, el desarrollo y la seguridad nacional, pública y fronteriza.

En este artículo de la Ley de Migración se plantea la política migratoria del Estado mexicano, bajo los principios de privilegios, reconocimiento y respeto a los Derechos Humanos de los migrantes que se internan en nuestro país independientemente de su situación migratoria si es regular o irregular, en concordancia con esos principios de políticas migratorias y de Derechos Humanos los artículos $6^{\circ}$ y $7^{\circ}$ de la mencionada Ley, refieren al 
derecho y libertades que el Estado mexicano garantiza a los extranjeros, migrantes o nacionales sea cual fuere su origen, nacionalidad, con especial atención a grupos vulnerables como menores de edad, mujeres, indígenas, adolescentes y personas de la tercera edad, así como a víctimas del delito; asimismo, señala como principio de política migratoria, la responsabilidad compartida entre las naciones; facilitación de la movilidad internacional de personas; complementariedad de mercados laborales; reconocimiento de derechos adquiridos; unidad familiar; e integración social y cultural.

\section{EL DERECHO DE LOS EXTRANJEROS A UTILIZAR LA SEGURIDAD SOCIAL}

La seguridad social en su máxima expresión y sentido ha sido una gran aspiración del ser humano, sentirse seguro en y durante la vida, respeto a lograr su libertad, igualdad y dignidad, en lo individual y colectivo, la seguridad social, que estructura las medidas de previsión y las normas por las que unos seres humanos asumen el compromiso de determinada conducta en aras de garantizar a otros su seguridad futura. (Ruiz Moreno, 2011).

Es así, que en la seguridad social comprende la asistencia pública como una función del Estado para proteger dentro de la sociedad a la población de los riesgos que traen las enfermedades, insalubridad, el abandono, la contaminación ambiental que afectan la salud de los individuos; la asistencia social, a través del conjunto de normas y acuerdos que toma el Estado en colaboración con particulares destinadas a procurar ayudas a personas imposibilitadas para procurarse por sí mismas requieren de la ayuda y socorro de otros; la previsión social, como el conjunto de acciones públicas o privadas destinadas a la protección de la población en general, trabajadores y sus familias, contra las contingencias o desastres que provengan de situaciones imprevistas.

En México la Ley de los Seguros Sociales, define que los seguros sociales son el instrumento básico de la seguridad social, de orden público y de interés nacional. Dentro de las prerrogativas de derechos sociales que la Carta Magna de 1917 reconoció una de ellas fue la previsión social, así lo contemplo el original artículo 123 constitucional, por eso tenemos que hablar de una transición de la previsión social a la seguridad social, porque hasta 1931, la Constitución sólo refería que los Estados tenías que tomar medidas para la previsión social, a través de cajas populares, después de esta fecha se reconoció la Ley de los seguros sociales como de orden público, en el apartado "A", fracción XXIX del citado artículo de la Constitución Federal.

Los extranjeros por el hecho de ser personas tienen derecho al reconocimiento de sus derechos humanos, así como a las garantías para su protección, en la clasificación de los Derechos Humanos de la persona se encuentran los derechos civiles y políticos, pero también los derechos económicos, sociales y culturales, es así, que el Derecho a la Seguridad Social tiene como finalidad garantizar el derecho humano a la salud, a la asistencia médica y a proporcionar a la persona medios de subsistencia, en lo individual y colectivo a través de las instituciones previamente establecidas para tal fin.

Consecuentemente, si un extranjero se encuentra en el Estado mexicano, y ha desempeñado una actividad laboral lícita, ello le da derechos a gozar de la seguridad social, aunque para desempeñar esa actividad o trabajo no tuviera la calidad migratoria regular, pues cabe destacar que la seguridad social al igual que los derechos humanos tienen el principio de universal, esto porque las personas no por el hecho de pasar de un país a otro dejan de tener las necesidad que son inherentes a las personas, como el enfermarse, el de padecer contingencia de subsistencias. 
Así que conforme a lo previsto en el artículo $1^{\circ}$ Constitucional del Estado mexicano, en el que reconoce el derecho a todas las personas de gozar de los derechos humanos reconocidos en la misma, no distingue a los nacionales de los extranjeros, y al estar contemplado en el artículo 123 apartado A, fracción XXIX de la misma Constitución, el Derechos de la Seguridad Social, es obvio que los extranjeros también deben gozar de ese derecho. De esto también se infiere que la Ley fundamental incita a eliminar todo trato diferenciado a personas en igualdad de condiciones (Islas Colín, 2002), en aplicación a los principios de derechos humanos de universalidad, progresividad, interdependencia e indivisibilidad.

A este respecto la Declaración Universal de Derechos Humanos (1948) en el Artículo 1. Refiere que "Toda persona tiene todos los derechos y libertades proclamados en esta Declaración, sin distinción alguna de raza, color, sexo, idioma, religión, opinión política o de cualquier otra índole, origen nacional o social, posición económica, nacimiento o cualquier otra condición." En el diverso artículo 25 refiere expresamente a la seguridad social y los derechos que comprende.

Artículo 25.-1. Toda persona tiene derecho a un nivel de vida adecuado que le asegure, así como a su familia, la salud y el bienestar, y en especial la alimentación, el vestido, la vivienda, la asistencia médica y los servicios sociales necesarios; tiene asimismo derecho a los seguros en caso de desempleo, enfermedad, invalidez, viudez, vejez u otros casos de pérdida de sus medios de subsistencia por circunstancias independientes de su voluntad.

2. La maternidad y la infancia tienen derecho a cuidados y asistencia especiales. Todos los niños, nacidos de matrimonio o fuera de matrimonio, tienen derecho a igual protección social.

En esto protege los derechos de los extranjeros a gozar de todos los derechos humanos en el que incluye el derecho a la seguridad social. En un espíritu similar se puede interpretar el Pacto Internacional de Derechos Económicos, Sociales y Culturales (1966), que en el Artículo 9 dice: "Los Estados Partes en el presente Pacto reconocen el derecho de toda persona a la seguridad social, incluso al seguro social". El Protocolo adicional a la Convención Americana sobre Derechos Humanos en materia de Derechos Económicos Sociales y Culturales, reconoce el derecho a la Seguridad Social en el Artículo 9 que en su texto dice:

Derecho a la Seguridad Social 1. Toda persona tiene derecho a la seguridad social que la proteja contra las consecuencias de la vejez y de la incapacidad que la imposibilite física o mentalmente para obtener los medios para llevar una vida digna y decorosa. En caso de muerte del beneficiario, las prestaciones de seguridad social serán aplicadas a sus dependientes. 2. Cuando se trate de personas que se encuentran trabajando, el derecho a la seguridad social cubrirá al menos la atención médica y el subsidio o jubilación en casos de accidentes de trabajo o de enfermedad profesional y, cuando se trate de mujeres, licencia retribuida por maternidad antes y después del parto.

Del precepto convencional se advierte la definición y alcances del derecho a la seguridad social que es proteger a la persona humana que se encuentra trabajando cubrir al menos la atención médica y el subsidio o jubilación en casos de accidente de trabajo o de enfermedad profesional, en el caso de la mujer trabajadora protege al producto y a la madre, otorgando las licencias o incapacidades por maternidad antes y después del parto.

Otro instrumento internacional que reconoce derechos de los migrantes en materia de seguridad social es el Convenio 102 de la Organización Internacional del Trabajo, al referir en la Parte XII." Igualdad de Trato a los Residentes no Nacionales," y en el artículo 681. "Los residentes no nacionales deberán tener los mismos derechos que los residentes nacionales. Sin embargo, podrán prescribirse disposiciones especiales para los no nacionales y para los nacionales nacidos fuera del territorio del Miembro, en lo que respecta a las 
prestaciones o partes de prestaciones financiadas exclusivamente o de manera preponderante con fondos públicos, y en lo que respecta a los regímenes transitorios."

La Convención Internacional sobre la Protección de los Derechos de todos los trabajadores Migratorios y de sus Familiares, en los artículos 1.1., 2 y 27 dispone que será aplicable a todos los trabajadores migratorios y a sus familiares sin distinción origen nacional, étnico o social, pero especialmente en el artículo 1.2. Dice: "La presente Convención será aplicable durante todo el proceso de migración de los trabajadores migratorios y sus familiares, que comprende la preparación para la migración, la partida, el tránsito y todo el período de estancia y de ejercicio de una actividad remunerada en el Estado de empleo, así como el regreso al Estado de origen o al Estado de residencia habitual." En el artículo 2.1. Dice que: "trabajador migratorio" es toda persona que vaya a realizar, realice o haya realizado una actividad remunerada en un Estado del que no sea nacional." Y en artículo 27 textualmente cita:

Artículo 27, 1. Los trabajadores migratorios y sus familiares gozarán en el Estado de empleo, con respecto a la seguridad social, del mismo trato que los nacionales en la medida en que cumplan los requisitos previstos en la legislación aplicable de ese Estado o en los tratados bilaterales y multilaterales aplicables. Las autoridades competentes del Estado de origen y del Estado de empleo podrán tomar en cualquier momento las disposiciones necesarias para determinar las modalidades de aplicación de esta norma. 2. Cuando la legislación aplicable no permita que los trabajadores migratorios o sus familiares gocen de alguna prestación, el Estado de que se trate, sobre la base del trato otorgado a los nacionales que estuvieren en situación similar, considerará la posibilidad de reembolsarles el monto de las contribuciones que hubieren aportado en relación con esas prestaciones.

Del texto transcrito, no queda la menor duda que el citado instrumento internacional otorga una protección amplia a los trabajadores migrantes y a sus familiares en seguridad social, sobre todo que traspasa el límite de las leyes nacionales y refiere que las autoridades competentes del Estado de origen y del Estado de empleo podrán tomar en cualquier momento las disposiciones necesarias para determinar las modalidades de aplicación de ese convenio, lo que a veces es lamentable es la falta de voluntad de las autoridades a veces para cumplir la protección y otorgamiento de los derechos a los nacionales o extranjeros en temas como normas de derecho del trabajo y de derecho de seguridad social.

De ahí, que el Poder Judicial de la Federación a través del Primer Tribunal Colegiado en materia Administrativa y del Trabajo del Décimo Primer Circuito, al resolver el Amparo directo 561/2013, sostuvo que de la interpretación conforme de los artículos 1o. de la Constitución Política de los Estados Unidos Mexicanos, cuando alude a que todas las personas gozarán de los derechos humanos reconocidos en ella y en los tratados internacionales de los que el Estado Mexicano sea parte, sin discriminación motivada por razón de raza, religión, origen étnico o nacional, género, edad, discapacidades, condición social, condiciones de salud, opinión, preferencias sexuales, estado civil o cualquier otra que atente contra la dignidad humana y tenga por objeto anular o menoscabar los derechos y libertades de las personas; a los instrumentos internacionales antes citado, así como de la Opinión Consultiva OC-18/03, sobre la Condición Jurídica y Derechos de los Migrantes Indocumentados, los migrantes acorde a los principios de igualdad y no discriminación, con independencia de su situación migratoria tienen derecho a disfrutar de los derechos derivados de la seguridad social, aun cuando carezca de permiso para laborar en el Estado mexicano (SEGURIDAD SOCIAL, 2014).

Para finalizar, con esta exposición se deja claro que el individuo que no es nacional en México y tiene la calidad de extranjero, ya sea por haber prestado un trabajo personal 
subordinado o por el simple hecho de ser persona humana tiene derecho a gozar de la seguridad social, en los términos que dispone el artículo 123 apartado "A”, fracción XXIX de la Ley Federal del Trabajo, conforme a los servicios que prestan las instituciones de seguridad social, que pueden ser el Instituto Mexicano del Seguro Social, el Instituto de Seguridad Social y Servicios de los Trabajadores del Estado, la Secretaría de Salud o Seguro Popular, el Instituto de Seguridad Social de las Fuerzas Armadas de México, o los Institutos de Seguridad Social de los Estados.

\section{CONCLUSIONES}

Primera. Que el derecho a la seguridad social es un derecho humano, que tiene como finalidad garantizar el derecho humano a la salud, otorgar medios de protección como el pago de subsidios, indemnización o pensión en caso de enfermedad o accidentes de trabajo, así como medios de subsistencias en los individual o colectivo a la persona para que enfrente las contingencias a las que se haya expuestas.

Segunda. Los extranjeros en la interpretación conforme al artículo $1^{\circ}$ de la Constitución Política de los Estados Unidos Mexicanos, al disponer que todas las personas gozarán de los derechos humanos reconocidos en dicha Constitución y en los tratados internacionales de los que el Estado Mexicano sea parte, así como de las garantías para su protección, se concluye que al instituirse el derecho a la seguridad social en el artículo 123, apartado A, fracción XXIX, constitucional, acorde con los principios de igualdad y no discriminación, al igual que en el artículo 6 de la Ley de Migración, que garantiza el ejercicio de los derechos y libertades de los extranjeros reconocidos en la Constitución, así como en los instrumentos internacionales, con independencia de su situación migratoria, tienen derecho a gozar de los derechos derivados de la seguridad social, por lo que la circunstancia de que una persona extranjera desatienda las disposiciones administrativas de índole migratorio, ello no puede repercutir en el desconocimiento de sus derechos laborales y tampoco en los beneficios de aquélla, ya que éstos surgen por el hecho de haber desempeñado un trabajo, con el que se genera una aportación a la generación de riqueza en el país y es suficiente para que sea acreedor de tales beneficios, aun cuando carezca de permiso para laborar en México.

Tercera. Por último debo reconocer que con las últimas reformas que se han hecho en materia de Derechos Humanos en México, no sólo se están encontrando los mecanismos para que los mexicanos accedan a sus derechos sociales, sino que además, se están teniendo herramientas para reclamar la protección, respeto y reconocimiento de los derechos de los individuos que por necesidades de la vida tienen que dejar su nación y migrar a otras naciones en busca de oportunidades para su desarrollo de vida, a los que a veces no les va bien a muchos como podemos enterarnos por noticias y por estadísticas, por eso valoro y aprecio mucho este medio para poder divulgar en estas líneas este tema de seguridad social de los extranjero en México.

\section{BIBLIOGRAFÍA}

ARREDONDO GALVÁN, F. X. (2005). "Internación ilegal estancia de los extranjeros en México". Revista Mexicana de Derecho, 7: 65-117.

CASTAN TOBEÑAS, J. (1992). Los derechos del hombre. Madrid: REUS, S.A. 
DERECHOS FUNDAMENTALES de acceso a la información pública y de petición. No pueden limitarse ni restringirse mediante el empleo de apercibimientos por parte de las autoridades, aun cuando se hubieren ejercido dentro de un procedimiento administrativo, IV.2o. a.59k (10a) (Tribunal Colegiado de Circuito Mayo de 2014).

EXTRANJEROS. (2012). Su derecho de acceso efectivo a la justicia se encuentra garantizado por el Estado Mexicano, por lo que éste debe proveer las medidas necesarias e idóneas para permitirle su ejercicio pleno, III.3o.t.4k (10a) (Tercer Tribunal colegiado en materia de trabajo del tercer circuito, 23 de Agosto de 2012).

FEDERACIÓN, D. O. (24 de mayo de 2011). Ley de Migración. Mexico.

INEGI. (2011). Conociendo: nos todos, Censo de Población y vivienda 2010, vol. 1, nº 2, México.

ISLAS COLÍN, A. (2002). "Derechos fundamentales conceptos" en http://www.Alfredoislas.com/ articulo.php.

ROBLES FARÍAS, D. (1998). “¿Pueden los Tratados internacionales regular la condición jurídica de los extranjeros en el derecho mexicano?" Derecho Privado, n 27, septiembre-diciembre, pp. 129 y ss.

RUÍZ MORENO, A. G. (2011). Nuevo derecho de la seguridad social. México: Porrúa.

SEGURIDAD SOCIAL. (2014). Los extranjeros tienen derecho a los beneficios derivados de ella si han desempeñado un trabajo, aún cuando omitan cumplir con las disposiciones administrativas de índole migratorio y carezcan de permiso para laborar., XI.1o.A.T.18L (10a) (Primer Tribunal Colegiado en Materia Administrativa y de Trabajo del Décimo Primer Circuito. 9 de Enero de 2014).

SOBERANES, J. L. e ISLAS, A. (2013). Locuciones latinas jurídicas. México: Porrúa.

VENEGAS TREJO, F. (2004). "Ciudadanía” Enciclopedia Jurídica Mexicana, T.II. C. México: Porrúa. WITKER, J. (2000). Derecho de los extranjeros. México: UNAM.

\section{Breve currículo:}

\section{Egla Cornelio Landero}

Maestría de Derecho Constitucional, Amparo y Derechos, Humanos; Maestría en Resolución de Conflictos y Mediación, por la Universidad Juárez Autónoma de Tabasco, México; y Master en Gestión y Resolución de Conflictos por la Universidad de Barcelona. Doctoranda del programa de posgrado Doctorado en Métodos de Solución de Conflictos y Derechos Humanos, en la Universidad Juárez Autónoma de Tabasco, México. Miembro del Padrón y Sistema Estatal de Investigadores en el Estado de Tabasco; Académica de Número de la Academia de Derecho del Trabajo y de la Previsión Social en México. Líneas de investigación Mecanismos de Solución de Conflictos y Derechos Humanos; Conflictos laborales y Seguridad Social. Profesora Investigadora de la Universidad Juárez Autónoma de Tabasco, México

\footnotetext{
Alfredo Islas Colín

Profesor Investigador Nacional, Miembro del Sistema Nacional de Investigadores del CONACYT, (SNI, nivel III); Doctor en Derecho Constitucional por la Université Panthéon-Assas, París II; Maestría en Derecho Constitucional por la misma Universidad de París II; Maestría en Derecho Constitucional por la Universidad de Castilla-La Mancha; y la Licenciatura en Derecho por la Facultad de Derecho de la UNAM. Profesor de la Universidad Juárez Autónoma de Tabasco y la Facultad de Derecho de la UNAM. Tiene la Página de Internet, www.alfredoislas.com.
} 